\title{
Wall to Wall Horizontal Connection for Precast Concrete Structures
}

\author{
Mousa Abdullah Mohammed Hasan, Rahimah Muhamad
}

\begin{abstract}
Precast concrete wall is one of the prefabricated components of high demands in the construction industry especially in residential buildings as it combines the benefit of rapid speed of construction, good quality control and minimum labour intensity at the construction site. Precast wall is produced in forms of wall panels and connected in the construction site to form an integrated structural element called precast concrete wall. However, the connection of wall panels is a key factor as it provides the structure integrity and robustness of the overall structural system. Therefore, this paper aims to describe and summarize types of precast wall-to-wall horizontal connection in terms structural behaviours such as embedded length, bonding stress, seismic behaviours and modes of failure. A total number of ten (10) out of eighteen (18) papers will be reviewed and discussed. The findings show that loop connection is suitable for seismically stabile zones as it is not capable to withstand lateral load action effectively whereas wire rope connection has insufficient ductility as the load-carrying capacity is governed by yielding of the lock bar and crushing of the joint mortar. Furthermore, $U$-shaped steel channel connection, the connection was developed for seismic zones. Providing $U$-shaped rubber in between the $U$-shape steel channel has made the connection more flexible with energy dissipater system.
\end{abstract}

Keywords: Precast concrete wall-to-wall connection; structural behaviours of precast wall-to-wall horizontal connections; mode of failure of precast wall-to-wall horizontal connections.

\section{INTRODUCTION}

Precast concrete wall is one of the prefabricated components of high demands in the construction industry especially in residential buildings as it combines the benefits of rapid speed of construction, good quality control and minimum labour intensity at the construction site. In Malaysia, precast concrete structure using prefabricated components has gained its popularity because of several advantages such as high quality of structural prefabricated components, less labour intensity at the construction site and shorter completion time of a project [8]. However, the connection of precast wall is a key factor as it provides the structure integrity and robustness of the overall structural system. Regardless of the method of connection in jointing the

Revised Manuscript Received on November 05, 2019.

*Corresponding Author:

Mousa Abdullah Mohammed Hasan*, Department of Engineering, Razak Faculty of Technology and Informatics, Universiti Teknologi Malaysia, Kuala Lumpur, 54100, Malaysia

Email: hasanmousaabdullah@gmail.com

Rahimah Muhamad, Department of Engineering, Razak Faculty of Technology and Informatics, Universiti Teknologi Malaysia, Kuala Lumpur, 54100, Malaysia reinforcement bars in precast structures, the connections must have the ability to provide the strength and the structural integrity under serviceability and ultimate limit states as well as to ensure continuity between the connected parts [10]. Precast wall panels are connected by means to form an integrated structure that can withstand gravity and lateral load action due to wind or earthquake excitation. As precast wall is considered the main global structural system when the precast wall panels subject to gravity and lateral load actions, the connection of the wall panels shall be designed to resist gravity and lateral load action due to wind and earthquake excitation. Furthermore, precast concrete wall panels combine the benefit of controlling verticality as it minimizes the eccentricity of vertical loading which in return reduces the additional potential moment, acting as a lateral resisting structural system in seismic regions and transferring the construction industry towards advance technology. Precast technology is also known as an industrialized construction process which involves manufacturing of concrete structural elements off site followed by transportation to the construction site to be assembled and joined using specially designed connections [12].

The horizontal connection of precast concrete wall-to-wall is of significantly important as it ensures the continuity of load transfer of the connected wall panels [17]. On the other hand, as precast components are fabricated offsite, onsite activity is limited to the assembly of components by lifting equipment [2]. Therefore, the assembly process mainly depends on the connection between the precast components to ensure the load transfer between the connected parts and secure the structural integrity of the complete structure. On the other hand, the main function of precast connection is to transfer the forces between the connected parts of precast components to obtain structural interaction of structural elements once the structural system is loaded [11]. Thus, the connection is regarded an essential part of the structural system as the stability of the structure mainly relies on the performance of the connection. Fig. 1 shows the load path of the global forces when the precast wall panels subject to lateral actions. It can be seen that when the precast wall panels subject to lateral actions, there will be shearing in the vertical and horizontal direction. Therefore, shear of precast wall due to wind and earthquake excitation is very crucial.

This paper investigated the structural behaviours of three types of precast wall to wall horizontal connection i.e. loop connection, wire rope and U-shape steel channel connection in terms of embedded length, bonding stress, seismic behaviours and modes of failure. A

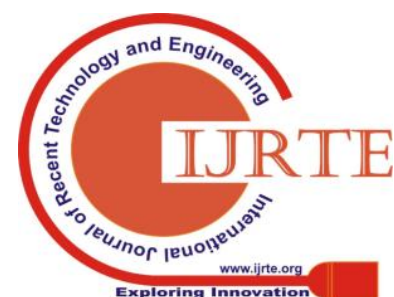


total number of ten (10) out of eighteen (18) papers will be reviewed and discussed. The findings of those papers will be discussed in the next section.
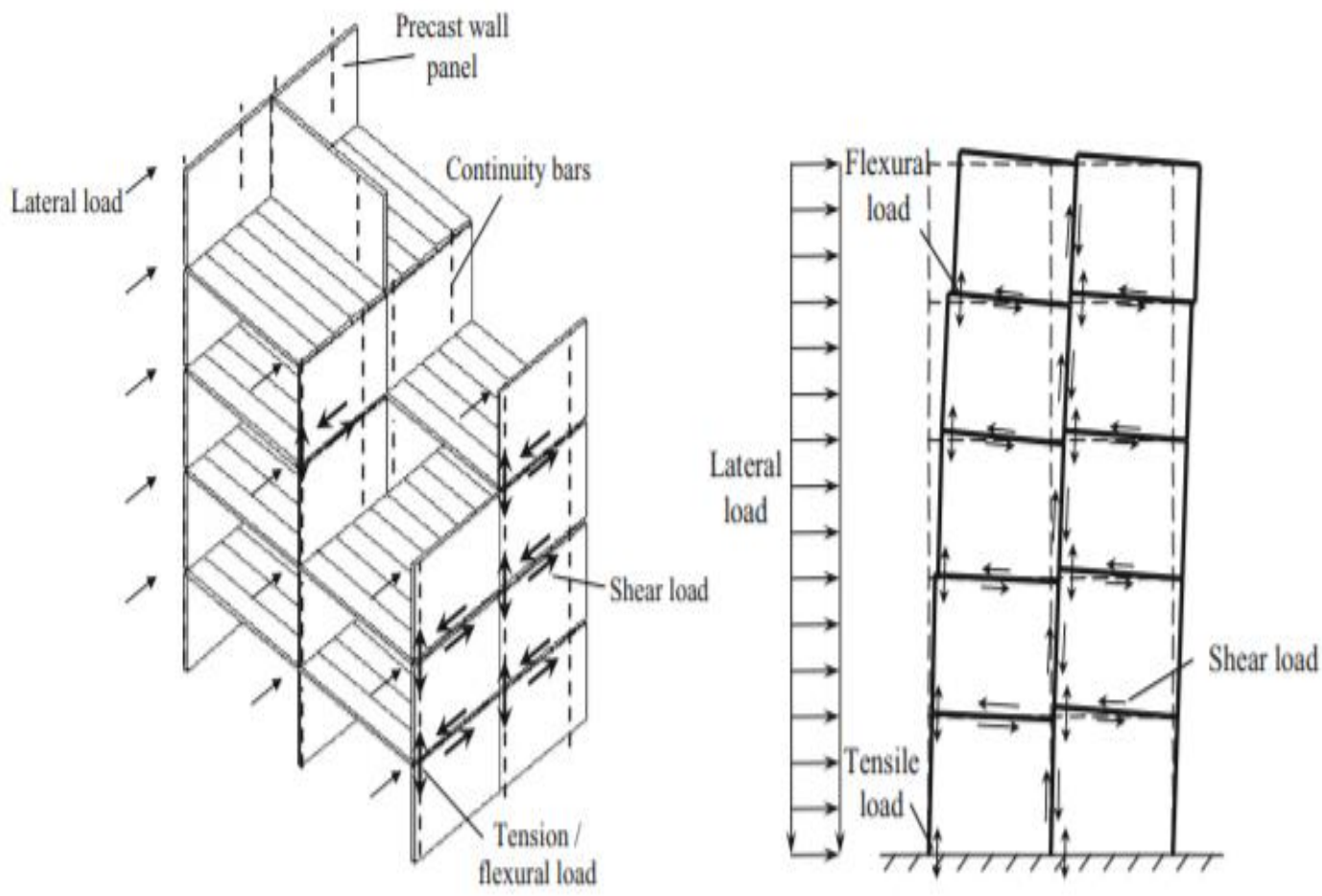

Figure 1: Wall panel force transfer under later load (Ling et al, 2011)

\section{TYPES OF WALL TO WALl HoRIZONTAL CONNECTION}

Many researchers such [1, 8, 10] have carried out extensive researches on investigating the behaviors of precast wall to wall vertical connection compare to wall to wall horizontal connection. In the current decade, few types of wall to wall horizontal connections have been introduced to the construction industry such loop connection, wire loop and U-shape steel channel. The structural behaviors of loop connection have been investigated by $[2,11,13,17]$ in terms of anchorage length, bonding and tensile. The section is to shed the light on types of precast wall to wall horizontal connections and their structural behaviours.

\section{A. Loop Connection}

In loop connection, the joint is located between two precast wall panels. However, there are two configurations of loop shaped bars in terms orientation i.e. classical design and new design Sørensen et al, 2017. In the classical design, the U-bar is placed perpendicular to the plane of the wall elements while in the new design the U-bar is placed perpendicular to the plane of the wall elements as shown in Fig. 2 and 3 respectively. Furthermore, the joint consists of loop-shaped rebar anchorages into wall panel during casting of precast wall panels and cast in situ concrete to form an integrated wall. As loop shaped bars are protruding out from the connected part of precast wall by lap splicing in the intermediate joint, the connection is activated once the joint is grouted by cast in situ concrete or mortar [11]. The purpose of loop-shaped anchorage is to decrease the length of lapping rebar [2]. In addition, another advantage of using loop connection is that the loop-shaped anchorage is capable of transferring the stresses between the reinforcement and concrete over a shorter length compare to straight rebar. On the other hand, the loop connection can be adopted for precast concrete structures as the width of the connection's joint is minimized and the material and labour costs involved are reduced. The fining of loop connection is summarized in Table 1. Four (4) out of 10 papers have been reviewed and discussed the structural behaviours of wall to wall horizontal connection in terms of embedded length, bonding stress, seismic behaviours and modes of failure.

In the new design of loop connection, the U-bar is placed in the same plane with the precast elements and reinforced transversely with $\mathrm{T}$-headed rebar to enhance the tension transfer between the connected precast walls Sørensen et al. (2017). Furthermore, this technique will enable the joint to transfer the shear by interlock action as the strut-ties action takes place. According to Sørensen et al. (2017) placing the U-bar parallel to the connected elements improves the shear loads carrying capacity and ductility performance of the connection as the U-bars are stressed to yielding. However, the details of U-bar in the new design needs to be further improved to make sure that the core of grout becomes strong enough to enable tensile yielding of U-bars and prevent premature concrete/mortar failure is the Sørensen et al. (2017) 


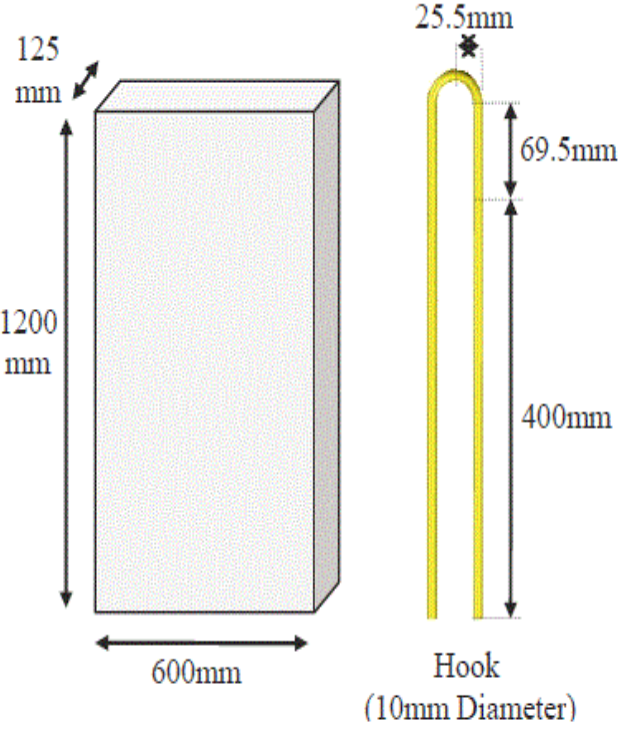

(a) Geometry of right/left panel and hook ( $\mathrm{mm})$

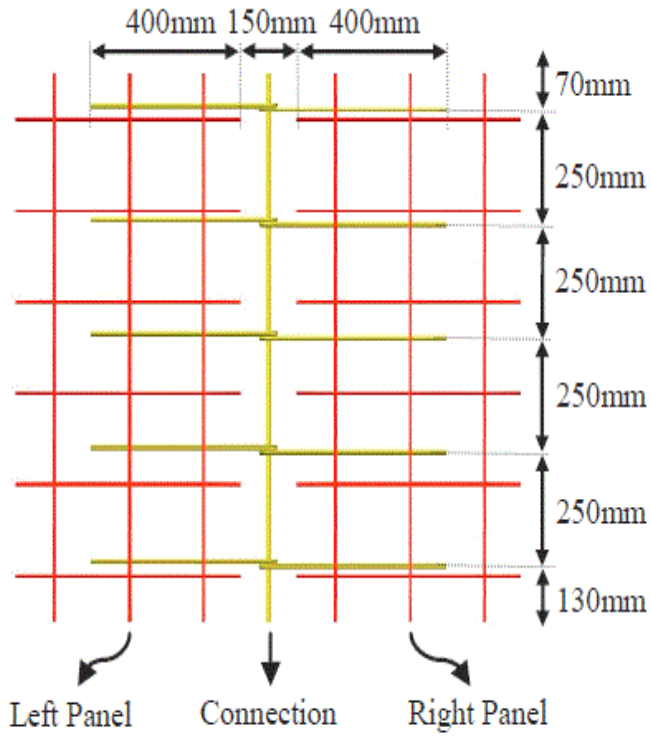

(b) Reinforcement detailing (mm)

Figure 2: Wall to wall loop connection (Vaghei et al, 2013)

(a)

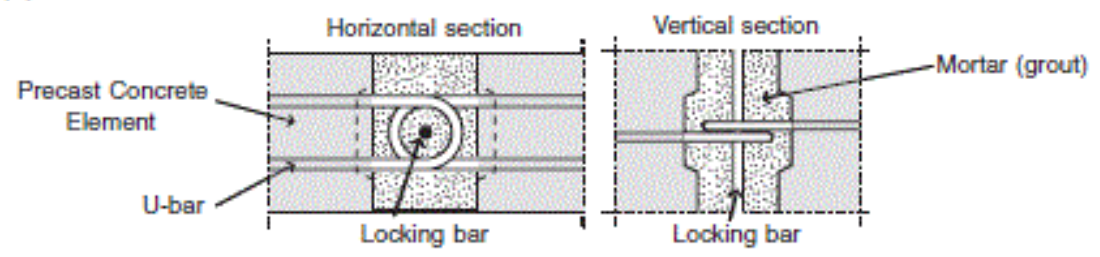

(b)

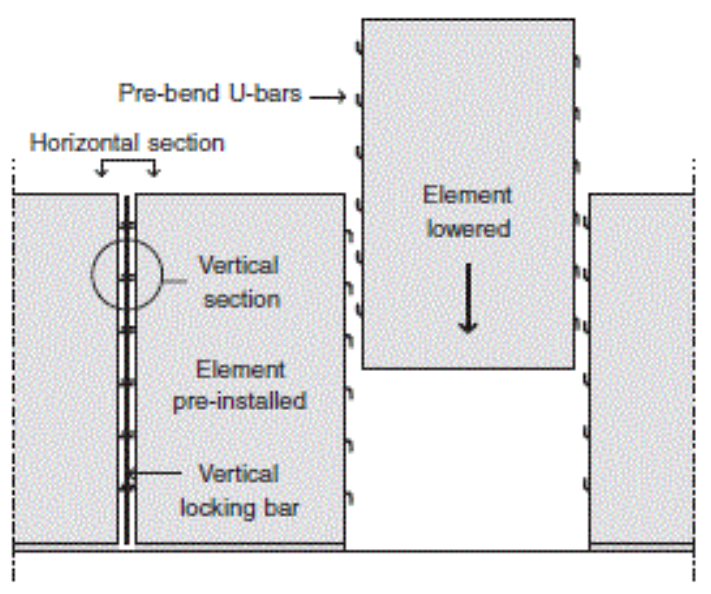

Figure 3: (a) Conventional shear connection design and (b) illustration of procedure for assembling of precast elements Sørensen et al. (2017

In conventional method, maintaining the structural continuity in reinforced concrete structures, steel bars normally placed adjacently to be lapped. Practically, lapping of steel bars is not suitable for precast structures as it requires longer length. In this context, loop-shaped rebar is practical option as the length of lapping rebar is decreased [2]. In normal straight bar, the transmission of forces will be through bond stress. In loop-shaped rebar, beside bond stresses, as shown in Fig. 3, there will be radial stresses transmitting to the concrete through compression [2]. In addition, the tensile strength of a loop connection may either be governed by yielding of the U-bars or by failure in the joint concrete [7].

The structural behaviors of loop connection can be further improved by the addition of steel fiber to the joint. As the presence of steel fiber in the loop connection increases ductility, tensile strength and bonding strength and improves deformation properties of the concrete, the possibility of reducing the anchorage length can be advantageous [2]. On the other hand, the use of steel fiber can also significantly reduce 
the possibility of splitting of the concrete in the loop's plane. However, the fiber alone did not ensure a ductile behaviour as the capacity decreased once the concrete material failed [3]. Furthermore, as the splitting is large in the plane of loops, placing transverse reinforcement through the lapping part of the loop can prevent the premature brittle failure of the loop connection.

In loop connection, the overlapping area of the U-bar loops, the spacing of the loops, the strength of the joint material and, finally, the transverse reinforcement in the overlapping area influence the tensile capacity [13]. Therefore, the preferred mode of failure for the loop connection is yielding of reinforcement rather that crushing of mortar. Thus, to obtain a strong connection, the overlapping loop area is reinforced and the joint area is grouted on-site with a concrete or a mortar and the connection is preferably designed for reinforcement yielding and not concrete failure [13]. Furthermore, the ductility and redundancy of precast concrete wall should be considered in the design process to decrease costs and ensure serviceability of precast concrete structures in seismic regions as horizontal joints at the floor level are considered as weak links in a structural system, [15].

Based on findings shown in Table 1, loop connection is practical option for precast concrete wall as the width of the joint is minimized. However, it is suitable for seismically stable zones as it is not capable to withstand lateral load due to earthquake excitation. Furthermore, special consideration shall be paid to the splitting of the joint mode of failure by strengthening the material of the joint to further improve the structural behaviours of the connection in terms of ductility, bonding stress and tensile strength.

(a)

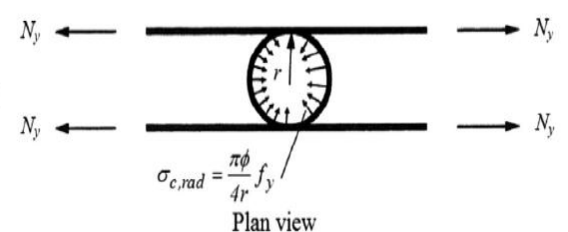

(b)

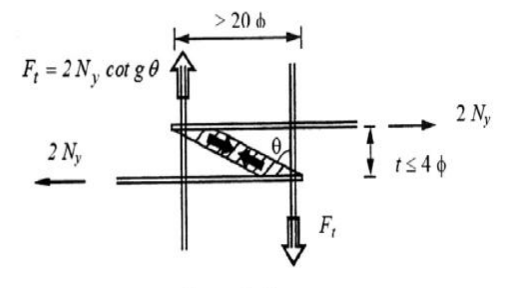

Lateral view

Figure 4: Transfer of forces at the loop connection: (a) radial stresses, and (b) inclined compressed struts between the overlapped loops (Araújo et al, 2016)

Table 1: Loop connection for precast wall to wall horizontal connections

\begin{tabular}{|c|c|c|}
\hline Authors & Findings & Mode of Failures \\
\hline Sørensen et al, 2016 & $\begin{array}{l}\text { - The connection is preferably designed for } \\
\text { reinforcement yielding and not concrete failure. } \\
\text { - The connection reinforced with precast fiber } \\
\text { reinforced dowels is more ductile with regular } \\
\text { mortar. }\end{array}$ & $\begin{array}{l}\text { - Crushing of concrete core } \\
\text { - Ductile failure of joint }\end{array}$ \\
\hline Araújo et al, 2014 & $\begin{array}{l}\text { - The length of lapping rebar is decreased. } \\
\text { - Capable to transfer the stresses between the } \\
\text { reinforcement and concrete over a shorter length. } \\
\text { - The width of the connection's joint is minimized. } \\
\text { - The presence of steel fiber increases ductility, } \\
\text { tensile strength and bonding strength }\end{array}$ & $\begin{array}{l}\text { - Splitting of the concrete in the } \\
\text { loop's plane. } \\
\text { - Local crushing of the joint } \\
\text { mortar. }\end{array}$ \\
\hline Rossley et al, 2014 & $\begin{array}{l}\text { - Loop connection is brittle. } \\
\text { - The connection has insufficient shear capacity. } \\
\text { - Lack of ductility. } \\
\text { - Insufficient lapping length } \\
\text { - Low strength of joint materials. }\end{array}$ & $\begin{array}{l}\text { - Premature brittle failure. } \\
\text { - Shear failure. }\end{array}$ \\
\hline Vaghei et al, 2013 & $\begin{array}{l}\text { - The loop connection is not capable to withstand } \\
\text { lateral load action. } \\
\text { - Cracking on the bond between the wall panel and } \\
\text { the joint. }\end{array}$ & $\begin{array}{l}\text { - Rupture of wall panel interface } \\
\text { and cast in situ joint. }\end{array}$ \\
\hline
\end{tabular}

\section{B. Wire Ropes Connection}

Wire rope connection was firstly introduced in 2014 as a replacement to the conventional loop shaped bar connection [6]. In wire rope connection, the conventional loop shaped bar is replaced by looped wire rope. The looped wire rope which is protruded out from the precast wall is preinstalled in wire box in the precast wall before casting. As shown in Fig. 5, the looped wire rope is spliced in the intermediated joint and locks by vertical bar and fills with cast in situ concrete or mortar to form an integrated precast wall. Once the intermediate joint is filled with concrete or mortar, the preinstalled box will function as shear key and spliced looped wire rope will function as transverse reinforcement that replaces the looped shaped U-bars [7]. Furthermore, the wire rope is more flexible as it has virtually no bending stiffness, which makes vertical installation of the precast wall much easier.

The current wire rope connections exhibit a very brittle failure mode as the wire 
ropes do not fulfil the Eurocode 2 requirements for ductility [6]. On the other hand, the wire ropes that currently are available in the construction industry have a very brittle tensile failure without any yield plateau in the stress-strain relationship [6]. Therefore, it is proposed to design the wire ropes as strong links to avoid such mode of failure. However, the load-carrying capacity of the joint will in this way be governed by yielding of the lock bar in combination with crushing of the joint mortar [4]. This design approach will ensure a warning of failure, especially if the mortar is confined. small diameter, the transfer of tension force between the overlapping wire rope may be limited by local crushing of joint mortar [5]. Therefore, the wire rope shall be stressed to tension to transfer the shear across the connection. In this context, the mode of failure can be predicted by the degree of transverse reinforcement. In case of low transverse reinforcement, the yield line will be through surface and cutting through the wire box. Table 2 summarized the findings of three (3) out of ten (10) papers that have been reviewed and discussed wire ropes connection in terms of embedded length, bonding stress and modes of failure.

As wire rope has high tensile strength with relatively

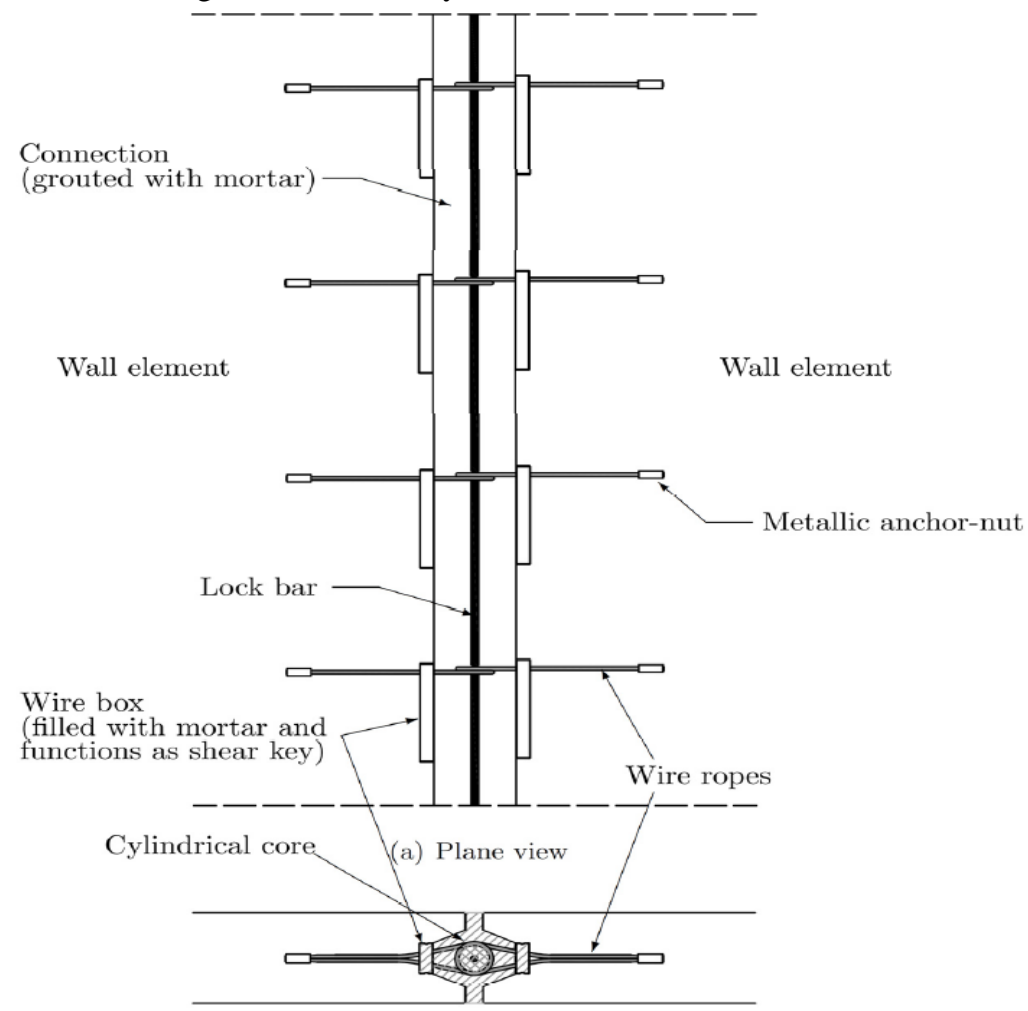

(b) Cross sectional view

Figure 5: Wire loop connection between two wall elements (Joergensen \& Hoang, 2015)

Table 2: Wire ropes for precast wall to wall horizontal connections

\begin{tabular}{|c|c|c|}
\hline Authors & Findings & Mode of Failures \\
\hline $\begin{array}{l}\text { Joergensen et al, } 2017 \\
\text { \& Joergensen \& } \\
\text { Hoang, } 2015\end{array}$ & $\begin{array}{l}\text { - Load-carrying capacity is governed by yielding of the } \\
\text { lock bar and crushing of the joint mortar. } \\
\text { - Lack of ductility. } \\
\text { - Has higher tensile capacity with relatively small } \\
\text { diameter. } \\
\text { - Wire rope can be used in shear connections as it has } \\
\text { tensile strength more than } 1000 \mathrm{MPa} \text {. } \\
\text { - Transfer of tension force may be limited by local } \\
\text { crushing of joint mortar. }\end{array}$ & $\begin{array}{l}\text { - Yielding through the } \\
\text { surface and cutting } \\
\text { through wore box. } \\
\text { - Diagonal yielding } \\
\text { running across. }\end{array}$ \\
\hline Joergensen et al, 2013 & $\begin{array}{l}\text { - The wire ropes do not fulfil the Eurocode } 2 \\
\text { requirements for ductility }\end{array}$ & $\begin{array}{l}\text { - Very brittle failure in } \\
\text { uniaxial tension }\end{array}$ \\
\hline
\end{tabular}

\section{U-Shape Steel Channel Connection}

U-shaped steel channel connection was firstly introduced and investigated under rotational loading in 2016 [14]. 
The connection comprises of male and female c-channel, rubber, hooks, nuts and screw. The hooks are welded to the c-channel and anchorage into precast wall panel and the rubber is place in between the c-channels forming energy dissipation system as shown in Fig. 6. In this type of connection, the assembly process requires minimum work in the construction site. In precast connection, ensuring the integration the connection between the precast elements is of significant concern as it ensures the stability of buildings when subjected to dynamic loads from earthquakes excitation, vehicles, and machineries [16].

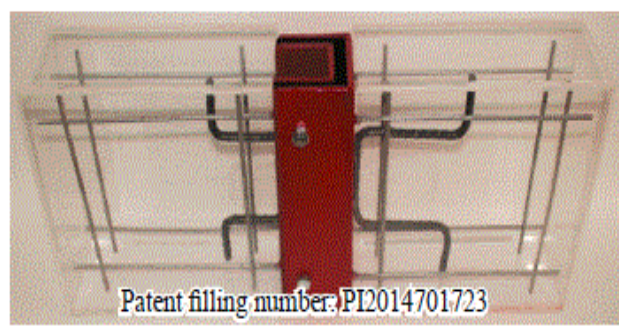

(a) Prototype of U-shaped steel channel connection

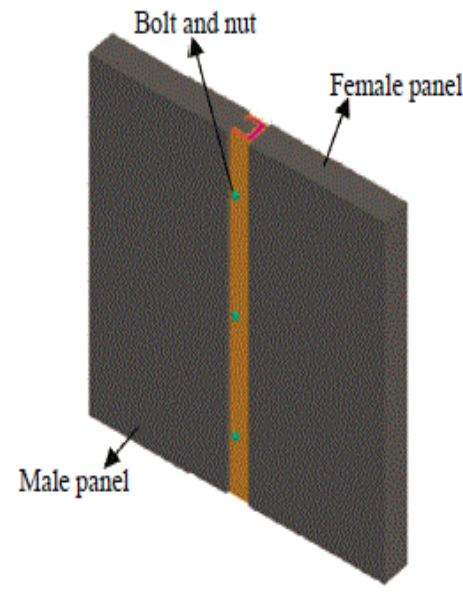

(b) General view of the proposed connection

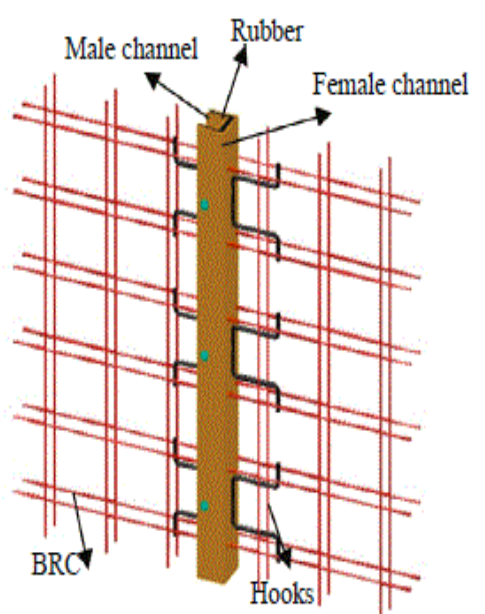

(c) Reinforcement in the proposed connection

Figure 6: U-Shape steel channel connections (Vaghei et al, 2017)

In the proposed U-shaped steel channel, the connection was developed for seismic zones. The presence of U-shaped rubber in between C-channel steel provides energy dissipation system which makes the connection more flexible and able to dissipate vibration effects due to earthquake excitation. Furthermore, in the proposed U-shaped steel channel connection, the connection has higher capacity when subjected to lateral load than loop connection, thereby improving its flexibility behaviours in all directions [15].

Based on previous researchers' findings shown in Table
3, further improvement shall be made for the proposed U-shaped steel channel connection to avoid concrete failure of wall panel in the minor direction as it is not a preferred mode of failure. In precast wall connection, it is preferably to design the connection for reinforcement yielding not concrete failure [13]. Furthermore, as the efficiency of the connection rotation in all degree of freedom relies mainly on the functionality of U-shaped rubber, further improvement shall be made for functionality of U-shaped rubber as it is the main energy dissipater system.

Table 3: U-Shape steel channel connection

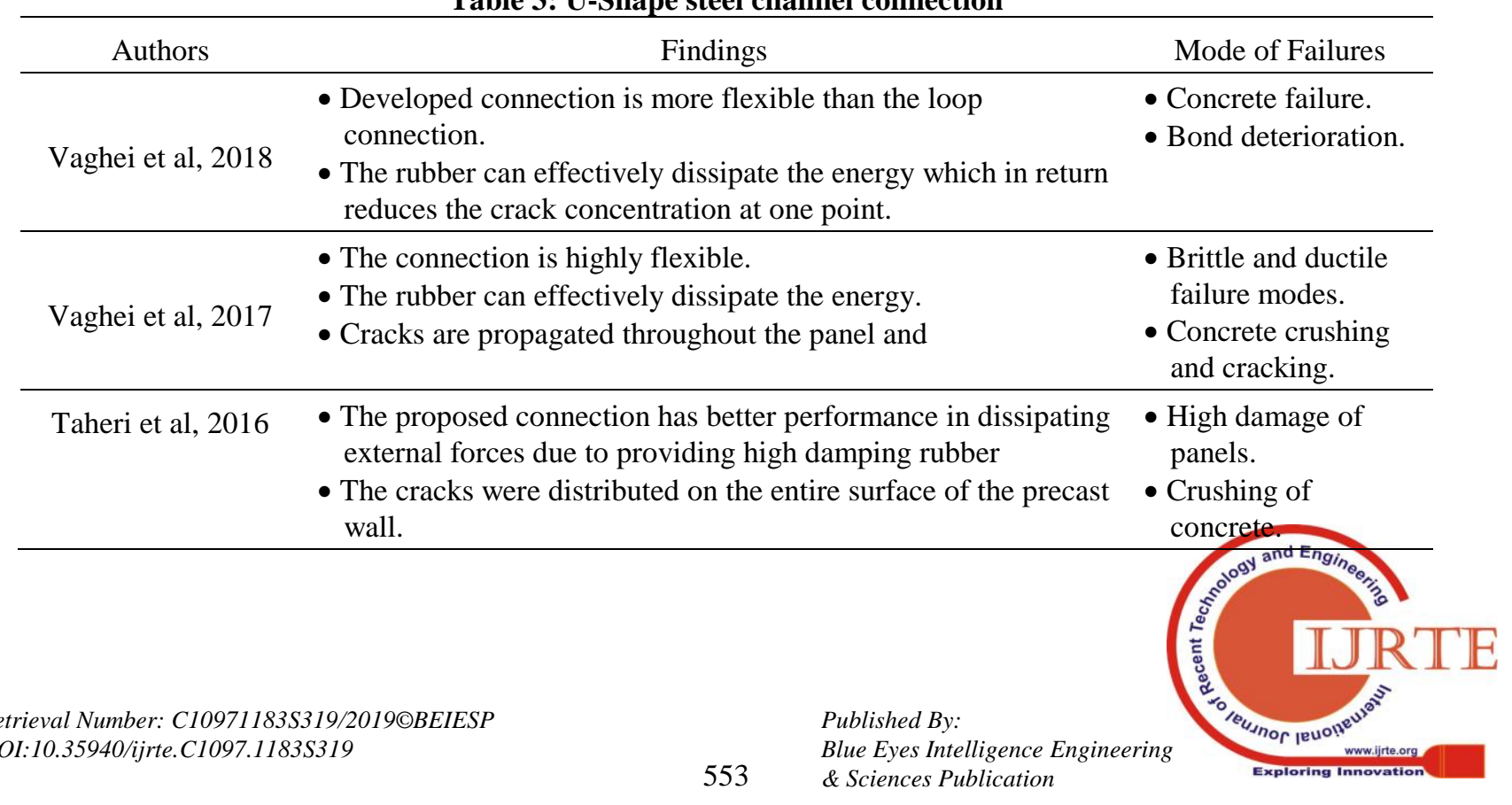




\section{CONCLUSION}

Currently, there are three types of precast wall-to-wall horizontal connections i.e. loop connection, wire rope and U-shape steel channel connection. Based on previous researchers' findings, in loop connection, loop shaped rebar is capable to transfer the stresses between the reinforcement bars and concrete over a shorter length. However, the loop connection is not capable to withstand lateral load action due to earthquake excitation as it has low ductility and insufficient shear capacity. In addition, loop connection reinforced with precast fiber reinforced dowels is more ductile than with regular mortar. Precast wall to wall connection is preferably designed for reinforcement yielding not concrete failure so that there will warning before the mode of failure occurs. In Wire rope connection, the connection has lack of ductility as the load-carrying capacity is governed by yielding of the lock bar and crushing of the joint mortar. However, wire rope has higher tensile capacity with relatively small diameter. For the developed U-shape steel channel, the connection is more flexible due to presence of U-shaped rubber between the U-shaped steel channels. Thus, the rubber can effectively dissipate the energy which in return reduces the crack concentration at one point.

\section{ACKNOWLEDGEMENTS :}

This work was financially supported by the Universiti Teknologi Malaysia GUP research grant number Q.K130000.2540.20H40.

\section{REFERENCES}

1. Alias, A., Sapawi, F., Kusbiantoro, A., Zubir, M. A., \& Rahman, A. A (2014). Performance of grouted splice sleeve connector under tensile load. Journal of Mechanical Engineering and Sciences (JMES), 7 , 1096-1102.

2. De Lima Araújo, D., Curado, M. C., \& Rodrigues, P. F. (2014). Loop connection with fibre-reinforced precast concrete components in tension. Engineering Structures, 72, 140-151.

3. Gordon, S. R. (2006). Joints for precast decks in steel concrete composite bridges (Doctoral dissertation, Heriot-Watt University).

4. Joergensen, H. B., Hoang, L. C., \& Hagsten, L. G. (2017). Strength of precast concrete shear joints reinforced with high-strength wire ropes. Institution of Civil Engineers. Proceedings. Structures and Buildings, 170(3), 168-179.

5. Jorgensen, H. B., \& Hoang, L. C. (2015). Load Carrying Capacity of Keyed Joints Reinforced with High Strength Wire Rope Loops Proceedings of fib symposium: Concrete-Innovation and Design.

6. Jørgensen, H. B. (2014). Strength of Loop Connections between Precast Concrete Elements: Part I: U-bar Connections Loaded in Combined Tension and Bending-Part II: Wire Loop Connections Loaded in Shear (Doctoral dissertation, Syddansk Universitet. Det Tekniske Fakultet).

7. Joergensen, H.B. and Hoang, L.C., 2013. Tests and limit analysis of loop connections between precast concrete elements loaded in tension. Engineering Structures, 52, pp.558-569.

8. Ling, J. H., Rahman, A. B. A., Ibrahim, I. S., \& Hamid, Z. A. (2017) An experimental study of welded bar sleeve wall panel connection under tensile, shear, and flexural loads. International Journal of Concrete Structures and Materials, 11(3), 525-540.

9. Ling, J. H. (2011). Behaviour of grouted splice connections in precast concrete walls subjected to tensile, shear and flexural loads (Doctoral dissertation, Universiti Teknologi Malaysia). Rahman, A. B. A., Yoon, L. H., Ibrahim, I. S., Mohamed, R. N., Mohammad, S., \& Saim, A. A. (2015). Performance of grouted splice sleeves with tapered bars under axial tension. In Applied Mechanics and Materials (Vol. 789, pp. 1176-1180). Trans Tech Publications.

10. Rossley, N., Aziz, F. N. A., Chew, H. C., \& Farzadnia, N. (2014). Behaviour of vertical loop bar connection in precast wall subjected to shear load. Australian Journal of Basic and Applied Science, 370-380.
11. Singhal, S., Chourasia, A., Chellappa, S., \& Parashar, J. Precast reinforced concrete shear walls: State of the art review. Structural Concrete.

12. Sørensen, J. H., Hoang, L. C., Olesen, J. F., \& Fischer, G. (2016) Tensile Capacity of U-bar Loop Connections with Precast Fiber Reinforced Dowels. In fib Symposium 2016: Performance-based approaches for concrete structures.

13. Taheri, H., Hejazi, F., Vaghei, R., Jaafar, M. S., \& Ali, A. A. A. (2016). New precast wall connection subjected to rotational loading. Periodica Polytechnica Civil Engineering, 60(4), 547-560.

14. Vaghei, R., Hejazi, F., Firoozi, A. A., \& Jaafar, M. S. (2018). Performance of Loop Connection in Precast Concrete Walls Subjected to Lateral Loads. International Journal of Civil Engineering, 17(3), 397-426.

15. Vaghei, R., Hejazi, F., Taheri, H., Jaafar, M.S. and Aziz, F.N.A.A 2017. Development of a new connection for precast concrete walls subjected to cyclic loading. Earthquake Engineering and Engineering Vibration, 16(1), pp.97-117.

16. Vaghei, R., Hejazi, F., Taheri, H., Jaafar, M. S., \& Ali, A. A. A (2013). Evaluate performance of precast concrete wall to wall connection. APCBEE procedia, 9, 285-290.

17. Sørensen, J. H., Hoang, L. C., Olesen, J. F., \& Fischer, G. (2017). Tensile capacity of loop connections grouted with concrete or mortar. Magazine of Concrete Research, 69(17), 892-904.

18. Sørensen, J. H., Hoang, L. C., Olesen, J. F., \& Fischer, G. (2017). Test and analysis of a new ductile shear connection design for RC shear walls. Structural concrete, 18(1), 189-204. 